Received: 11.10 .2018

Revised: 31.10 .2018

Accepted: 30.11 .2018

DOI: $10.17804 / 2410-9908.2018 .6 .184-190$

\title{
DEVELOPMENT OF TRIBOTECHNICAL MATERIALS BASED ON MIXTURES OF FLUOROPLASTS
}

\author{
P. N. Petrova ${ }^{\text {a) }}$ and O. V. Gogoleva ${ }^{\text {b)* }}$ \\ Institute of Oil and Gas Problems, SB RAS, \\ 20 Avtodorozhnaya St., Yakutsk, 677007, Russian Federation \\ a) iD https://orcid.org/0000-0002-1859-8034; \\ b) iD https://orcid.org/0000-0001-5425-2295 oli-gogoleva@yandex.ru \\ *Corresponding author. E-mail: oli-gogoleva@yandex.ru \\ Address for correspondence: 20 Avtodorozhnaya St., Yakutsk, 677007, Russian Federation
}

The paper presents the results of research on the development of self-lubricating materials based on polymer blends. It has been established that the complex modification of polytetrafluoroethylene with ultradisperse polytetrafluoroethylene and magnesium spinel leads to an up to 50 times decrease in the rate of mass wear, with a certain decrease in the coefficient of friction. It is shown that the addition of mechanocomposites based on zeolite and UPTFE leads to an increase in strength and elongation at break of materials by 20-30\% compared to the initial polymer. It has been established that PKM possesses optimal properties, with the content of the combined filler obtained by the joint activation of the components at a mass ratio of zeolite: polymer filler $=2: 1$. Compared to composites containing only activated zeolite in an amount of $2 \mathrm{wt} \%$, the developed composites with modified UPTFE zeolites at the same concentration 3 to 4 times excel in wear resistance.

Keywords: polymeric composite material, polytetrafluoroethylene, ultradisperse polytetrafluoroethylene, wear resistance, coefficient of friction, mechanocomposite, joint activation.

\section{References}

1. Ohlopkova A.A., Petrova P.N., Gogoleva O.V., Fedorov A.L. Fluoropolymer Composites of Tribotechnical Purpose. Trenie i Iznos, 2007, vol. 28, no. 6, pp. 627-633. (In Russian).

2. Okhlopkova A.A., Petrova P.N., Gogoleva O.V. Investigation of the triboengineering characteristics of nanocomposites based on polymeric blends. Journal of Friction and Wear, 2009, vol. 30, pp. 363-368. DOI: 10.3103/S1068366609050109.

3. Lipatov Yu.S. Fiziko-khimicheskie osnovy napolneniya polimerov [Physicochemical Foundations of Polymers Filling]. Moscow, Khimiya Publ., 1991. (In Russian).

4. Bryk M.T., Lipatova T.E. Fiziko-khimija mnogokomponentnykh polimernykh system [Physical Chemistry of Multicomponent Polymer Systems]. Naukova Dumka Publ., Kiev, 1986, 345 p. (In Russian).

5. Mashkov Yu.K., Ovchar Z.N., Baibaratskaya M.Yu., and Mamaev O.A. Polimernye kompozitsionnye materialy v tribotekhnike [Polymer Composition Materials in Triboengineering]. Moscow, Nedra-Biznestsentr Publ., 2004. (In Russian).

6. Ohlopkova A.A., Vinogradov A.V., Pinchuk L.S. Plastiki, napolnennye ul'tradispersnymi neorganicheskimi soedineniyami [Plastics Filled with Ultrafine inorganic Compounds]. Gomel, Inst. Mekh. Metallopolim. Sist. Publ., 1999. (In Russian). 
7. Argunova A.G., Petrova P.N., Okhlopkova A.A., Shadrinov N.V., Gogoleva O.V. Ultrasonication-Induced Changes in Physicomechanical and Tribotechnical Properties of PTFE Composites. Journal of the Korean Chemical Society, 2015, vol. 59, no. 3. DOI: 10.5012/jkcs.2015.59.3.233.

8. Okhlopkova A.A., Vasil'ev S.V., Petrova P.N., Gogoleva O.V. Frictional basalt-reinforced polymers based on polytetrafluoroethylene. Russian Engineering Research, 2016, vol. 36 (4), pp. 285-288. DOI: 10.3103/s1068798x16040134.

9. Belyi V.A., Sviridenok A.I., Petrokovets M.I., and Savkin V.G. Trenie i iznos materialov na osnove polimerov [Friction and Wear of Polymer-Based Materials]. Minsk, Nauka i Tekhnika Publ., 1976. (In Russian).

10. Gogoleva O.V. Development of machine-building tribotechnical materials based on polytetrafluoroethylene and natural zeolites from Yakut deposits. Synopsis of Thesis, Komsomolsk-na-Amure, 2009. (In Russian).

11. Petrova (Broshcheva) P.N. Development of machine-building tribotechnical materials based on polytetrafluoroethylene and natural zeolites from Yakut deposits. Synopsis of Thesis, Yakutsk, 2002. (In Rissian).

12. Gogoleva O.V., Okhlopkova A.A., Petrova P.N. Development of Self-Lubricating Antifriction Materials Based on Polytetrafluoroethylene and Modified Zeolites. Journal of Friction and Wear, 2014, vol. 35, no. 5, pp. 383-388. DOI: 10.3103/s1068366614050055. 
Подана в журнал: 11.10 .2018

УдК 621.891

DOI: $10.17804 / 2410-9908.2018 .6 .184-190$

\title{
РАЗРАБОТКА ТРИБОТЕХНИЧЕСКИХ МАТЕРИАЛОВ НА ОСНОВЕ СМЕСЕЙ ФТОРОПЛАСТОВ
}

\author{
П. Н. Петрова ${ }^{\text {a) }}$, О. В. Гоголева ${ }^{\text {) }}$ \\ Федеральное государственное бюджетное учреждение науки Институт проблем нефти и газа СО РАН, \\ ул. Автодорожная, 20, Якутск, Российская Федерация \\ a) iD https://orcid.org/0000-0002-1859-8034; \\ b) iD https://orcid.org/0000-0001-5425-2295 oli-gogoleva@yandex.ru \\ *Ответственный автор. Электронная почта: oli-gogoleva@yandex.ru \\ Адрес для переписки: 677007, Якутск, ул. Автодорожная, 20, Российская Федерация \\ Тел.: +7 (4112) 35-79-16
}

В статье представлены результаты исследований по разработке самосмазывающихся материалов на основе смесей полимеров. Установлено, что комплексное модифицирование политетрафторэтилена ультрадисперсным политетрафторэтиленом и шпинелем магния приводит к снижению скорости массового изнашивания до 50 раз при некотором снижении коэффициента трения, а добавление механокомпозитов на основе цеолита и УПТФЭ - к повышению прочности и относительному удлинению при разрыве материалов на 20-30 \% по сравнению с исходным полимером. Установлено, что оптимальными свойствами обладают ПКМ с содержанием комбинированного наполнителя, полученного совместной активацией компонентов при массовом соотношении цеолит/полимерный наполнитель равном 2:1. По сравнению с композитами, содержащими только активированный цеолит в количестве 2 мас. \%, разработанные композиты с модифицированным УПТФЭ цеолитов в той же концентрации превосходят по износостойкости в 3-4 раза.

Ключевые слова: полимерный композиционный материал, политетрафторэтилен, ультрадисперсный политетрафторэтилен, износостойкость, коэффициент трения, механокомпозит, совместная активация.

\section{1. Введение}

Комплексное модифицирование полимеров неорганическими наполнителями в сочетании с органическими - одно из перспективных направлений в полимерном материаловедении. Введение в полимерную матрицу, содержащую полимерные или олигомерные добавки, неорганического модификатора позволяет решить проблему повышения адгезионной прочности на границе раздела фаз полимер-наполнитель $[1,2]$. Введение дисперсного наполнителя в полимерные смеси приводит к образованию граничных слоев на поверхности раздела с наполнителем, однако эти граничные слои будут образованы всеми компонентами полимерной смеси. Совершенно очевидно, что свойства наполненной полимерной смеси будут определяться структурой и составом граничных слоев, энергией взаимодействия каждого из компонентов с поверхностью, а также распределением частиц наполнителя между двумя составляющими фазами и в межфазной области.

Таким образом, введение наполнителя в бинарную смесь приводит к образованию граничного слоя, отличающегося по составу от состава матрицы в объеме. Это изменение состава уже само по себе является одним из факторов, определяющих изменение совместимости в бинарной системе при введении наполнителя. Возникают две области - вблизи границы раздела и не затронутая действием поверхности матрица, отличающиеся по составу и, 
следовательно, по совместимости. Естественно, что преимущественное взаимодействие одного из компонентов с поверхностью наполнителя должно способствовать фазовому разделению в системе. Объединение граничащего с наполнителем слоя смеси одним из компонентов можно рассматривать как фазовое разделение в микрообъемах, прилегающих к твердой поверхности $[3,4]$.

Особенности полимер-полимерных систем заключается прежде всего в том, что адгезионные явления на границе раздела двух полимерных фаз существенно отличаются от явлений на границе полимер-твердое тело (с высокой поверхностной энергией). Полимерынаполнители и полимерные среды (или связующие), как и все полимерные системы, характеризуются низкими значениями поверхностной энергии, и поэтому смачивание поверхности полимерного наполнителя полимерным связующим может быть неполным.

Политетрафторэтилен в исходном состоянии имеет низкий уровень тех или иных физико-механических свойств: прочности, жесткости, износостойкости и т. д. Поэтому их модифицируют введением различных наполнителей-модификаторов, создавая полимерные композиционные материалы с более высокими показателями эксплуатационных свойств [5-8].

\section{2. Материалы и методика}

Объектами исследования являются политетрафторэтилен (ПТФЭ) марки ПН-80 (ГОСТ 10007-80), ультрадисперсный политетрафторэтилен (УПТФЭ) (плотность 2140-2170 кг/ $\mathrm{m}^{3}$, температура плавления кристаллов $\left.270-290{ }^{\circ} \mathrm{C}\right)$. В качестве наполнителей были применены нанодисперсный шпинель магния (ШМ), полученная плазмохимическим синтезом (разработка Института химии твердого тела и механохимии СО РАН). Особенности использованного наполнителя - высокая дисперсность (размер частиц порядка 70-80 нм) и развитая удельная поверхность $\left(170 \mathrm{~m}^{2} / \Gamma\right)$; плотность $3580 \mathrm{\kappa г} / \mathrm{M}^{3}$, температура плавления $2135{ }^{\circ} \mathrm{C}$. Также в качестве наполнителя использована природная цеолитовая порода Кемпендяйского месторождения Республики Саха (Якутия). Цеолиты представляют собой алюмосиликаты общей формулы $\mathrm{Me}_{2 / n} \mathrm{O} \times \mathrm{Al}_{2} \mathrm{O}_{3} \times \mathrm{xSiO}_{2} \times \mathrm{yH}_{2} \mathrm{O}$, где $\mathrm{Me}$ - щелочной или щелочноземельный металл; $\mathrm{n}-$ степень его окисления.

Физико-механические характеристики - предел прочности при растяжении $\left(\sigma_{\mathrm{p}}\right)$ и относительное удлинение при разрыве $\left(\varepsilon_{\mathrm{p}}\right)$ определяли на испытательной машине «UTS-2» (Германия) по ГОСТ 11262-80 при температуре $23 \pm 2{ }^{\circ} \mathrm{C}$ и относительной влажности $50 \pm 5 \%$, скорость перемещения подвижных захватов - $100 \pm 10$ мм/мин. Количество образцов на одно испытание - 5. В качестве образцов использовали лопатки типа II.

Скорость массового изнашивания и коэффициент трения по стандартной методике (ГОСТ 11629 - 75) на серийной машине трения СМЦ-2. Использована схема трения вал втулка (образец - втулка с внешним и внутренним диаметром 34 и 26 мм соответственно, высотой 20 мм, контртело - стальной вал из стали 45 с твердостью 45-50 HRS и шероховатостью $\mathrm{R}=0,06-0,08$ мкм) при удельном давлении 0,45 МПа, скорости скольжения 0,39 м/с; время испытания 3 ч. Втулки перед началом испытаний обрабатывали этиловым спиртом, взвешивали на аналитических весах, фиксировали значение массы втулки до и после трения. Скорость массового изнашивания находили по формуле:

$$
I=\Delta m / t
$$

где $\Delta m=m_{1}-m_{2}$, мг; $m_{1}-$ масса втулки до испытания, мг; $m_{2}-$ масса втулки после испытания, мг; $t$ - время испытания, ч.

\section{3. Обсуждение результатов исследований}

Для улучшения деформационно-прочностных свойств ПТФЭ была проведена его модификация ультрадисперсным политетрафторэтиленом (УПТФЭ), который в чистом виде 
характеризуется более высокими физико-механическими характеристиками. УПТФЭ вводили в различных концентрациях от 1 до 5 мас. \% (табл. 1). Выбор такой концентрации УПТФЭ связан с тем, что при создании полимер-полимерных гибридных систем вводимый полимер может рассматриваться как наполнитель, а введение наполнителя в больших концентрациях нецелесообразно, вследствие падения прочностных показателей полимерных композиционных материалов (ПКМ).

\section{Таблица 1 - Механические и триботехнические характеристики ПКМ на основе ПТФЭ +УПТФЭ и ПКМ на основе ПТФЭ+УПТФЭ, модифицированного наношпинелью магния}

\begin{tabular}{|c|c|c|c|c|c|}
\hline \multirow{2}{*}{ Состав композита } & \multicolumn{5}{|c|}{ Характеристики ПКМ } \\
\cline { 2 - 6 } & $\sigma$, МПа & $\varepsilon, \%$ & $E$, МПа & $I$, мГ/час & $f$ \\
\hline ПТФЭ & 20,0 & 320 & - & 78,0 & 0,15 \\
\hline $\begin{array}{c}\text { ПТФЭ + 1-5 мас. \% } \\
\text { УПТФЭ }\end{array}$ & $20-24$ & $320-390$ & $490-510$ & $90,0-105,0$ & $0,05-0,10$ \\
\hline $\begin{array}{c}\text { ПТФЭ + 1-3 мас. \% } \\
\text { УПТЭ + 1 мас. \% ШМ }\end{array}$ & $17-19$ & $320-450$ & $520-670$ & $8,6-11,1$ & $0,06-0,15$ \\
\hline $\begin{array}{c}\text { ПТФЭ+1-3 мас. \% } \\
\text { УПТФЭ + 2 мас. \% ШМ }\end{array}$ & $18-19$ & $315-400$ & $520-680$ & $1,6-2,2$ & $0,10-0,15$ \\
\hline
\end{tabular}

Примечание: $\sigma_{\mathrm{p}}$ - предел прочности при растяжении; $\varepsilon$ - относительное удлинение при разрыве; $E$ - модуль упругости; $I$ - скорость массового изнашивания; $f$ - коэффициент трения.

Из приведенных данных следует, что модифицирование ПТФЭ малыми добавками УПТФЭ приводит к повышению прочности и относительного удлинения при разрыве на 20-30\%. Увеличение деформационно-прочностных характеристик можно объяснить тем, что частицы УПТФЭ, локализуясь в межструктурной области ПТФЭ, способствуют росту подвижности проходных цепей макромолекул в неупорядоченных зонах и повышению общей подвижности элементов надмолекулярных [6].

Однако при улучшении деформационно-прочностных характеристик полимерных смесей зарегистрировано снижение триботехнических показателей, что вполне закономерно и объясняется увеличением доли пластичного и более плавкого материала в композите [9].

Для увеличения износостойкости полимерную смесь исследованного состава модифицировали наночастицами шпинели магния. В ранее проведенных работах $[6,10]$ многочисленными экспериментами подтверждено, что введение наношпинелей различных металлов в ПТФЭ приводит к существенному повышению износостойкости ПКМ - в 200-500 раз. Показано, что введение наношпинели магния в полимерную смесь приводит к увеличению модуля упругости композита (табл. 1), что свидетельствует о наличии прочной адгезионной связи между компонентами в гетерогенной системе. Зарегистрировано практическое сохранение деформационно-прочностных характеристик ПКМ на уровне исходного политетрафторэтилена, а по сравнению со свойствами полимерных смесей наблюдается некоторое снижение прочностных показателей. Можно предположить, что в последнем случае наночастицы создают дополнительные напряжения на границе раздела фаз.

Введение УПТФЭ сопровождается существенным снижением коэффициента трения, что может быть, с образованием трибохимической смазки на поверхностях трения (табл. 1). В работах $[1,9]$ показано, что трение ПТФЭ сопровождается реакциями окисления, деструкции, структурирования и др. процессами, приводящими к образованию на поверхности тре- 
ния вторичных структур. Определяющую роль играют газообразные и низкомолекулярные продукты трибодеструкции, выступающие в качестве трибохимической смазки.

Введение наноструктурного наполнителя в полимерную смесь при сохранении высоких значений деформационно-прочностных характеристик привело к уменьшению скорости массового изнашивания полимерных композитов в 20-50 раз. Это можно объяснить тем, что в процессе трения вследствие сдвиговых деформаций, повышения температуры и давления локализованные в подповерхностных слоях частицы шпинели магния выносятся на поверхность трения и предохраняют материал от изнашивания. Увеличение содержания ШМ до 2 мас. \% приводит к снижению скорости массового изнашивания в 40 раз по сравнению с исходным ПТФЭ и в 50 раз - по сравнению с полимерной смесью.

В работах $[11,12]$ доказана перспективность использования цеолитов в качестве наполнителей ПТФЭ. В связи с этим далее изучено влияние цеолита на свойства полимерной смеси ПТФЭ-УПТФЭ. Активированные в планетарной мельнице АГО-2 в течение 2 мин цеолиты далее подвергали совместной активации в различных массовых соотношениях и в различных концентрациях с УПТФЭ для их поверхностной модификации, улучшения диспергирования и предотвращения процессов агломерации в полимерной матрице. Активации цеолитов совместно с УПТФЭ должно привести к закреплению частиц полимера на поверхности цеолита, так как цеолиты обладают каркасно-пористой структурой и могут быть объемными носителями полимерных молекул, если размеры молекул или кинетических сегментов макромолекул соответствуют размерам пор цеолитов. Если учесть, что УПТФЭ содержит в своем составе низкомолекулярные фторуглероды, то вероятность их закрепления на поверхности цеолитов большая.

Результаты деформационно-прочностных и триботехнических исследований ПКМ на основе ПТФЭ и модифицированного УПТФЭ цеолита приведены в табл. 2. Установлено, что добавление механокомпозитов на основе цеолита и УПТФЭ приводит к повышению прочности и относительного удлинения при разрыве материалов на 20-30 \% по сравнению с исходным полимером. По критерию повышения деформационно-прочностных и триботехнических характеристик ПКМ выявлена оптимальная концентрация модифицированного УПТФЭ цеолита, соответствующая 2 мас. \%. Оптимальными свойствами обладают ПКМ с содержанием комбинированного наполнителя, полученного совместной активацией компонентов при массовом соотношении цеолит/полимерный наполнитель равном $2: 1$. По сравнению с композитами, содержащими только активированный цеолит в количестве 2 мас. \%, разработанные композиты с модифицированным УПТФЭ цеолитов в той же концентрации превосходят по износостойкости в 3-4 раза.

Таблица 2 - Механические и триботехнические характеристики ПКМ на основе ПТФЭ и модифицированного УПТФЭ цеолита

\begin{tabular}{|c|c|c|c|c|c|c|}
\hline \multirow{2}{*}{$\begin{array}{c}\text { Состав } \\
\text { композита }\end{array}$} & \multirow{2}{*}{$\begin{array}{c}\text { Массовое } \\
\text { соотношение } \\
\text { цеолит: УПТФЭ }\end{array}$} & \multicolumn{5}{|c|}{ Характеристики ПКМ } \\
\cline { 3 - 7 } & - & 20,0 & 320 & $460-470$ & 92,73 & 0,15 \\
\hline ПТФЭ & - & 22,0 & 350,0 & $500-510$ & 2,15 & 0,28 \\
\hline $\begin{array}{c}\text { ПТФЭ+2 мас. \% } \\
\text { цеолита }\end{array}$ & $1: 1$ & 18,8 & 245,2 & $570-575$ & 0,90 & 0,032 \\
\hline \begin{tabular}{c} 
ПТФЭ+5 мас. \% \\
(цеолит- \\
\cline { 1 - 5 } УПТФЭ)
\end{tabular} & $2: 1$ & 19,9 & 250,5 & $610-620$ & 0,10 & 0,164 \\
\hline
\end{tabular}

С повышением концентрации модифицированного цеолита до 5 мас. \% наблюдается снижение значений относительного удлинения при сохранении значений прочности на уровне композита с таким же содержанием только активированного цеолита. Введение мо- 
дифицированного наполнителя также приводит к увеличению модуля упругости композита, что свидетельствует о наличии прочной адгезионной связи между компонентами в гетерогенной системе и повышении жесткости макромолекул при введении модифицированного цеолита.

\section{4. Заключение}

На основании комплексного изучения свойств доказана перспективность комплексного модифицирования политетрафторэтилена. Установлено, что при модификации полимерных смесей на основе ПТФЭ+УПТФЭ наношпинелью магния износостойкость увеличилась в 20-50 раз при сохранении повышенных значений деформационно-прочностных характеристик.

Разработана технология получения комплексных наполнителей, заключающаяся в совместной механоактивации цеолита с УПТФЭ на планетарной мельнице. Установлено, что добавление механокомпозитов на основе цеолита и УПТФЭ приводит к повышению прочности и относительного удлинения при растяжении материалов на 20-30 \% по сравнению с исходным полимером. Установлено, что наибольшее снижение значений скорости массового изнашивания ПКМ с использованием комплексного наполнителя достигается в количестве 5 мас. \% при массовом соотношении цеолит/УПТФЭ равном 2:1. С увеличением концентрации наполнителя повышается износостойкость до 900 раз по сравнению с исходным полимером.

Разработаны полимерные композиционные материалы с повышенным комплексом эксплуатационных показателей.

\section{Литература}

1. Фторполимерные композиты триботехнического назначения / А. А. Охлопкова, П. Н. Петрова, О. В. Гоголева, А. Л. Федоров // Трение и износ. - 2007. - Т. 28, № 6. - С. 627-633.

2. Okhlopkova A. A., Petrova P. N., Gogoleva O. V. Investigation of the triboengineering characteristics of nanocomposites based on polymeric blends // Journal of Friction and Wear. 2009. - Vol. 30, № 5. - P.363-368. - DOI: 10.3103/S1068366609050109.

3. Липатов Ю. С. Физико-химические основы наполнения полимеров. - М. : Химия, 1991. - $260 \mathrm{c}$.

4. Брык М. Т., Липатова Т. Э. Физико-химия многокомпонентных полимерных систем. Киев : Наукова думка, 1986. - 345 с.

5. Полимерные композиционные материалы в триботехнике / Ю. К. Машков, 3. Н. Овчар, М. Ю. Байбарацкая, О. А. Мамаев. - М. : ООО «Недра-Бизнесцентр», 2004. - 262 с.

6. Охлопкова А. А., Виноградов А. В., Пинчук Л. С. Пластики, наполненные ультрадисперсными неорганическими соединениями. - Гомель : ИММС НАНБ, 1999. - 164 с.

7. Ultrasonication-Induced Changes in Physicomechanical and Tribotechnical Properties of PTFE Composites / A. G. Argunova, P. N. Petrova, A. A. Okhlopkova, N. V. Shadrinov, O. V. Gogoleva // Journal of the Korean Chemical Society. - 2015. - Vol. 59, no. 3. DOI: $10.5012 / \mathrm{jkcs} .2015 .59 .3 .233$.

8. Frictional basalt-reinforced polymers based on polytetrafluoroethylene / A. A. Okhlopkova, S. V. Vasil'ev, P. N. Petrova, O. V. Gogoleva // Russian Engineering Research. - 2016. Vol. 36 (4). - P. 285-288. - DOI: 10.3103/s1068798x16040134.

9. Трение и износ материалов на основе полимеров / В. А. Белый, А. И. Свириденок, М. И. Петроковец, В. Г. Савкин. - Минск : Наука и техника, 1976. - 432 с.

10. Гоголева О. В. Разработка триботехнических нанокомпозитов на основе сверхвысокомолекулярного полиэтилена, смесей фторопластов и шпинелей магния, меди, кобальта : автореф. дисс. канд. тех. наук : 05.02.01. - Комсомольск-на-Амуре, 2009. - 19 с.

11. Петрова (Брощева) П. Н. Разработка машиностроительных триботехнических материалов на основе политетрафторэтилена и природных цеолитов якутских месторождений : автореф. дисс. канд. тех. наук : 05.02.01. - Якутск, 2002. - 24c.

12. Gogoleva O. V., Okhlopkova A. A., Petrova P. N. Development of Self-Lubricating Antifriction Materials Based on Polytetrafluoroethylene and Modified Zeolites // Journal of Friction and Wear-2014. - Vol. 35, no. 5. - P. 383-388. - DOI: 10.3103/s1068366614050055. 